\title{
Electrocardiographic changes in a rare case of flecainide poisoning:
}

\section{a case report}

\author{
Andrea Rognoni*1, Marzia Bertolazzi ${ }^{1}$, Marzia Peron ${ }^{2}$, Sergio Macciò ${ }^{1}$, \\ Gemma Ternavasio Cameroni ${ }^{2}$, Angelo Gratarola ${ }^{2}$ and Giorgio Rognoni ${ }^{1}$
}

\begin{abstract}
Address: ${ }^{1}$ Department of Cardiology, Sant'Andrea Hospital, Corso Mario Abbiate 21, 13100, Vercelli, Italy and ${ }^{2}$ Emergency Department and Intensive Care Unit, Sant'Andrea Hospital, Corso Mario Abbiatr 21, 13100 Vercelli, Italy

Email: Andrea Rognoni* - arognoni@hotmail.com; Marzia Bertolazzi - marzia bert@yahoo.it; Marzia Peron - marzper@libero.it; Sergio Macciò - smac@yahoo.it; Gemma Ternavasio Cameroni - gtcam@yahoo.it; Angelo Gratarola - angie@libero.it; Giorgio Rognoni - giorgiorg@yahoo.it

* Corresponding author
\end{abstract}

Published: 3 December 2009

Cases Journal 2009, 2:9137 doi:10.1/86/1757-1626-2-9|37

This article is available from: http://www.casesjournal.com/content/2/1/9137

(C) 2009 Rognoni et al; licensee BioMed Central Ltd.

This is an Open Access article distributed under the terms of the Creative Commons Attribution License (http://creativecommons.org/licenses/by/2.0), which permits unrestricted use, distribution, and reproduction in any medium, provided the original work is properly cited.
Received: 19 October 2009

Accepted: 3 December 2009

\begin{abstract}
Flecainide is a class Ic anti - arrhythmic drug with sodium channel blocking activities. We report a case of a 57 year - old woman who attempted a suicide by ingesting approximately I,8 gr of flecainide. On the surface electrocardiogram this results in a large QRS complex and in prolongation of the QTc interval. Overdose with a class Ic drug is very uncommon, its management is difficult and the mortality high.

Because of a hemodynamic instability and in addition to supportive care and antidysrhythmics, she was treated with a high dose of sodium bicarbonate in hypertonic solution; after this infusion the patient's QRS progressive narrowed.

In conclusion, sodium bicarbonate may be useful in the treatment of widened QRS and to stabilize a overdose of class Ic anti - arrhythmic drugs.
\end{abstract}

\section{Introduction}

Flecainide is a Vaughn - Williams class IC antiarrhtythmic agent used for the treatment of supra - ventricular and, also, ventricular arrhythmias.

In some countries, such as United states, its use is limited because of known proarrhytmic effects [1]. Chemically, it causes a rate - dependent slowing of a rapid sodium channels slowing phase of depolarisation [2]. Flecainide, also, slows conduction in all cadiac fibres, increasing conduction times in the atria, ventricles, atrio - ventricular node and his - Purkinje system and can cause myocardial depression. Flecainide is cleared mainly by the liver at a relatively high rate $(5,6 \mathrm{ml} / \mathrm{kg}$ per minute) but its large value of distribution $(4,9 \mathrm{ml}(\mathrm{kg}))$ yields a large half - life of 11 hours [3]. Oral loading - dose 50 of flecainide is 50 - $498 \mathrm{mg} / \mathrm{kg}$ in rat; it is extensively metabolized mainly to $\mathrm{m}$ - O - dealkylated flecainide and the $\mathrm{m}$ - $\mathrm{O}$ - dealkylated lactam of flecainide; the first makes up to $20 \%$ of the drug's anti - arrhythmic activity. Furthermore flecainide is excreted mainly in urine (about 10 to $50 \%$ as the unchanged drug and the remainder as metabolites, depending on type of administration; about $5 \%$ is excreted in faeces).

Flecainide is a rare cause of suicide attempt by drug overdose; furthermore there are not specific antidote and no way of rapidly eliminating the drug from the body [4]. 
Commonly recommended therapies, including haemodialysis (in this case we can remove only $1 \%$ of unchanged flecainide), treatment with hypertonic saline solution and pacing, have not been shown to improve survival.

In the literature we find also some anecdotal case report of particularly therapy used to treat flecainide overdose. Timperly et al [5], in 2005, reported a case complicated by cardiogenic shock and treated with pharmacological inotropic support and intra - aortic balloon pump; in 48 hours both QRS and ventricular function had returned to normality.

Yasui et al [6], described, in a young woman, another possible approach such as peripheral cardiopulmonary bypass support (CBS) to maintain perfusion of the liver; this CBS successfully supported the patient until flecainide level decreased as a result of redistribution and normal clearance mechanisms.

We report a case of flecainide poisoning which was successfully treated with high dose of sodium bicarbonate in hypertonic solution.

\section{Case report}

A 57 year - old women with a history of previous supra ventricular tachyarrhythmia and chronic therapy with flecainide acetate (100 mg every day) without any cardiovascular risk factors, was admitted to our Emergency Department having ingested 18 tablets of flecainide acetate (equivalent to approx 1,8 gr) for a suicide attempt.

On admission she was responsive and conscious; pulse was $90 \mathrm{bpm}$ and blood pressure 110/70 $\mathrm{mmHg}$.

The first electrocardiogram (EKG) showed a sinusal rhythm with a large QRS complex (similar to a right blundle branch block) and a very long QT tract (about 500 msec.) (Figure 1).

The patient was carried into our Intensive Care Unit (ICU) and initially treated with oxygen and intravenous crystalloids. The results of the first arterial blood analysis were $\mathrm{PH} 7,472, \mathrm{PCO}_{2} 41,2 \mathrm{mmHg}, \mathrm{PO}_{2} 130 \mathrm{mmHg}$ (oxygen 4 $\mathrm{l} /$ minutes non invasive), HCO 29,8 ng/l. The hematochemical parameters were: $\mathrm{K}^{+} 3,5 \mathrm{mmol} / \mathrm{l}, \mathrm{Na}^{+} 143 \mathrm{mmol} /$ $\mathrm{l}, \mathrm{Cl}^{-} 103 \mathrm{mmol} / \mathrm{l}$. Flecainide serum levels after 30 minutes from admission were $1940 \mu \mathrm{g} / \mathrm{ml}$ (therapeutic range are $200-1000 \mu \mathrm{g} / \mathrm{ml})$.

Furthermore a therapy with instillation of $40 \mathrm{mg}$ of activated charcoal and $40 \mathrm{mg}$ of $\mathrm{MgSO}^{4}$ was started. Approximately 45 minutes after admission to our ICU the poison Centre of "San Matteo Hospital" at Pavia (far off $60 \mathrm{Km}$ ) was contacted; they suggested bolus of sodium bicarbo-

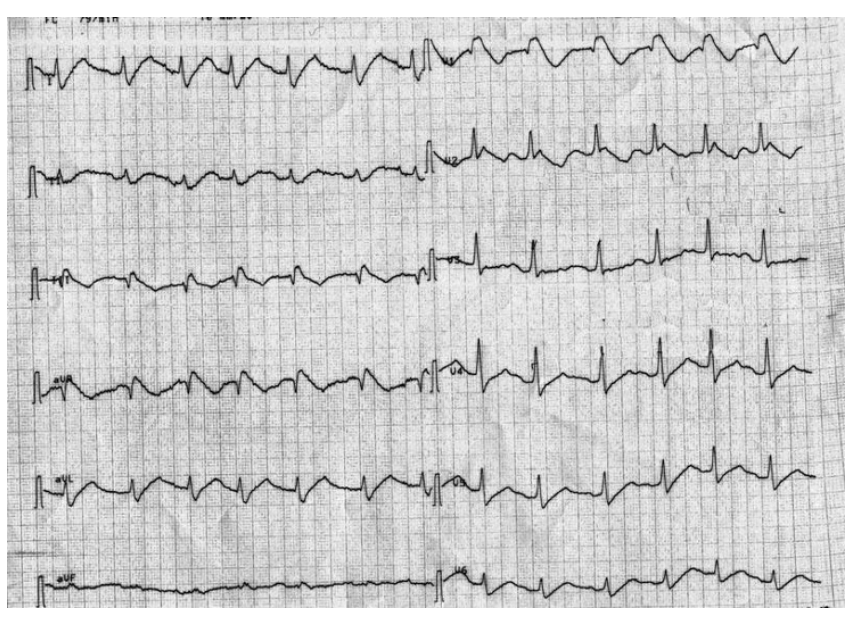

Figure I

The first electrocardiogram with a large QRS complex and a very long $Q T c$ interval.

nate $\left(\mathrm{NaCO}_{3}\right) 150 \mathrm{mEq}$ and $\mathrm{NaCO}_{3} 130 \mathrm{mEq}$ in slow infusion ( $1-2 \mathrm{MEq} / \mathrm{h})$ for 24 Hours.

Flecainide serum levels 6 hours after the beginning of this infusion were $990 \mu \mathrm{g} / \mathrm{ml}$

Good progress were made over the next 72 hours and no signs of organ dysfunction were evident. None were apparent and the EKG had returned to normality and a psychiatric referral was made (Figure 2). The serum concentration of flecainide progressively returned to normal (Figure 3) and four days after the overdose the patient was transferred to medical ward and after other three days she was discharged to home.

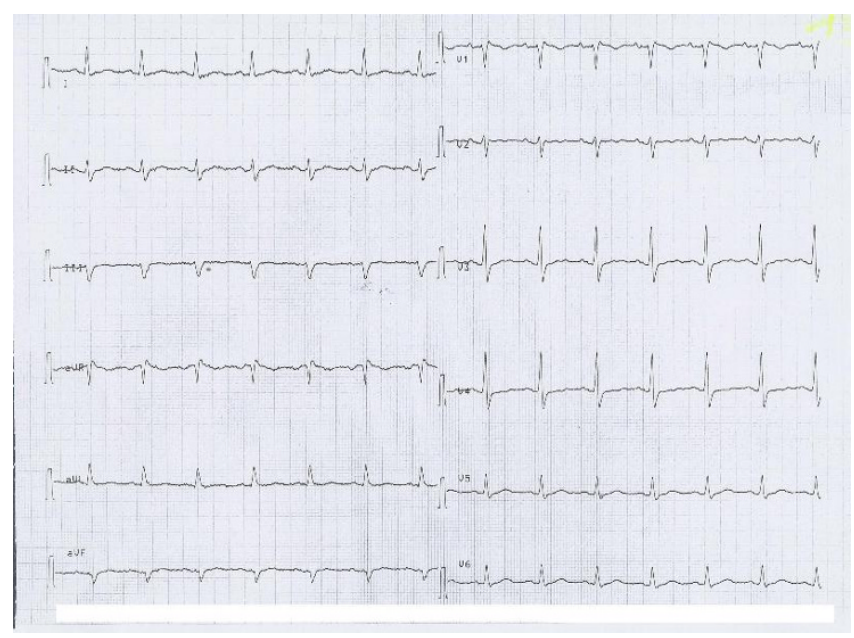

Figure 2

The pre - discharge electrocardiogram. 


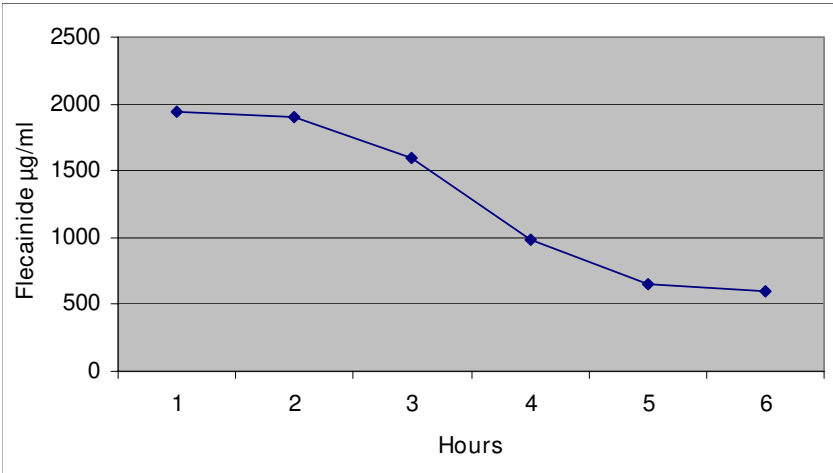

Figure 3

Flecainide levels during hospitalization.

\section{Discussion}

As far as we are aware, there are no previously reported cases of high dose of sodium bicarbonate being used to treat acute flecainide overdose. This drug is a class Ic anthyarrhythmic agent which acts by blocking sodium channels involved in cardiac depolarization; this results in marked suppression of the cardiac conduction system in addition to a moderate negative inotropic effect [7]. All these actions are manifest on the EKC by increased lenght of PR, QRS and QTc intervals.

The pharmacokinetics qualities of flecainide are high oral bioavaibility of $95 \%$ elimination, half - life seems variable with a quarter of the drug undergoing renal excretion unchanged [8] the remainder undergoes hepatic metabolism to inactive derivates.

The therapeutic range of flecainide is considered to be 200 - $1000 \mu \mathrm{g} / \mathrm{ml}$. In a toxic flecainide overdose, adverse cardiac effects including bradycardia, atrio - ventricular block, pulse less electrical activity and asystole can occur within 30 to 120 minutes of ingestion [9]. Treatment should be direct at decreasing gastrointestinal absorption through gastric emptying and administration of activate charcoal[9]; furthermore serum flecainide levels should be reduced through maintenance of organs perfusion which allows drug clearance and distribution.

In the literature many proarrhythmic effects of flecainide are described; they may be related to its promoting re entry in ventricular issue [9].

Worsening of existing ventricular arrhythmias or the onset of ones can occur in up to $30 \%$ of patients [10]

Because type Ic drugs such as flecainide produce both therapeutic and toxic effects due to extensive rate dependent sodium channel - blockade in the myocar- dium, attempt to treat toxicity with hypertonic sodium bicarbonate or molar lactate have been attempted in animals [11] and in humans $[8,9,12]$ with mixed success.

Keyler et al [11] showed, in rats treated with $6 \mathrm{mEq} / \mathrm{kg}$ of hypertonic sodium bicarbonate, reduced to $26 \%$ flecainide induced QRS prolongation. Like - wise, $5 \mathrm{mEq} / \mathrm{kg}$ of hypertonic sodium bicarbonate in dogs resulted in significant shortening of the QRS and his - ventricular intervals within 10 minutes [13]. Furthermore the same authors reported that of in dogs with pacing - induced dysarrhythmias after flecainide administration, 6 of 7 responded to hypertonic sodium bicarbonate, with only 1 of 7 responding to placebo[13]. Hypertonic sodium bicarbonate and sodium clorate work by increasing the extra cellular concentration of sodium displacing flecainide from its receptors sites either inside the selectivity filter of the fast sodium channels or at on external anaesthetic receptors site [14].

Because flecainide is a weak acid with a high pKa, alkalinization may also decrease the active - ionized fraction of flecainide necessary for sodium channels blockade. Chouty et al [15] used doses of $500 \mathrm{~mL}$ of $1 \mathrm{M}$ sodium lactate endovenous for more than 30 minutes to treat three cases of flecainide poisoning with rapid narrowing of the QRS interval and correction of hypotension, and another flecainide overdose responded to combination to a combination of $250 \mathrm{mmol}$ of hypertonic sodium bicarbonate, $136 \mathrm{mmol} \mathrm{NaCl}$ and physostigmine $2 \mathrm{mg}$ endovenous in the report of Wilkelman [9].

Our patient's dysarrhythmia did not resolve until sodium bicarbonate was administered.

All our observations suggest that sodium bicarbonate may be useful for the treatment of widened QRS and ventricular ectopy resulting from flecainide toxicity.

\section{Consent}

Written informed consent was obtained from the patient for publication of this case report and accompanying images. A copy of the written consent is available for review by the Editor-in-Chief of this journal.

\section{Competing interests}

The authors declare that they have no competing interests.

\section{Authors' contributions}

AR carried out the research about the effects of flecainide; $M B$ partecipated in the study of the sides effects of flecainide; MP performed the layout of the figures; GTC partecipated in the writing of the text; AG partecipated in the writing of the text; GR partecipated in the writing of the text. All authors read and approved the final manuscript. 


\section{References}

I. Roden DM, Woosley RL: Drug therapy: Flecainide. N EnglJ Med I986, 315:36-4I.

2. Wang Z, Fermini B, Nattel S: Mechanism of flecainide's rate dependet actions on action potential duration in canine atrial tissue. J Pharmacol Exp Ther 1992, 267(2):575-58I.

3. Funck-Brentano C, Becquemont L, Kroemer HK, Bühl K, Knebel NG, Eichelbaum M, Jaillon P: Variable disposition kinetics and electrocaridographic effects of flecainide during repeated dosing in humans: contribution of genetic factors, dose - dependent clearance, and interaction with amiodarone. Clin Pharmacol Ther 1994, 55:256-269.

4. Siegers A, Board PN: Amiodarone used in successful resuscitation after near - fatal flecainide overdose. Resuscitation 2002, 53:105-108.

5. Timperly J, Mitchell ARJ, Brown PD, West NEJ: Flecainide overdose - support using an intra - aortic balloon pump. $B M C$ emergency Medicine 2005, 5: 10.

6. Yasui RK, Culclasure TF, Kaufman D, Freed CR: Flecainide Overdose: Is Cardiopulmonary Support the treatment? Annals of Emergency Medicine 1997, 29:680-682.

7. Bourke JP, Cowan JC, Tansuphaswadikul S, Campbell RWF: Antiarrhythmic drug effects on left ventricular performance. Eur Heart J 1987, 8(Suppl A): I05-III.

8. Koppel C, Oberdisse U, Heinemeyer G: Clinical course and outcome in class Ic antiarrhythmic overdose. Clin toxicol 1990, 28:433-444.

9. Winkelmann BR, Leinberger H: Life - threatening toxicity: A pharmacodynamic approach. Ann Intern Med I 987, 106:807-8I4.

10. Gotz D, Pohle S, Freed CR: Extracorporeal pump assistance: novel treatment for acute lidocaine poisoning. Eur J Clin Pharmacol 1982, 22:129-135.

II. Keyler DE, Pentel PR: Hypertonic sodium bicarbonate partially reverses QRS prolongation due to flecainide in rats. Life Sci 1989, 264:1575-1580.

12. Pentel PR, Goldsmith SR, Salerno DM, Nasraway SA, Plummer DW: Effect of hypertonic sodium bicarbinate on encainamide overdose. Am J Cardiol 1986, 57:878-880.

13. Bajaj AK, Woosley RL, Roden DM: Acute electrophysiologic effects of sodium bicarbonate administration in dogs treated with O - desmethyl encainide. Circulation 1989, 80:994-1002.

14. Ranger S, Sheldon R, Femrini B, Natttel S: Modulation of flecainide's cardiac sodium channel blockade actions by extra cellular sodium: a possible cellular mechanism for the action of sodium salts in flecainide cardiotoxicity. J Pharmacol Exp Ther 1993, 264: | |60-1|167.

15. Chouty F, Funck-Brentano C, Landau JM, Lardoux H: Effectiveness of intravenous high dose molar lactate in flecainide poisoning. Presse Med 1987, 16:808-810.

Publish with Bio Med Central and every scientist can read your work free of charge

"BioMed Central will be the most significant development for disseminating the results of biomedical research in our lifetime. "

Sir Paul Nurse, Cancer Research UK

Your research papers will be:

- available free of charge to the entire biomedical community

- peer reviewed and published immediately upon acceptance

- cited in PubMed and archived on PubMed Central

- yours - you keep the copyright

Submit your manuscript here:

http://www.biomedcentral.com/info/publishing_adv.asp
BioMedcentral 